\title{
(6) OPEN ACCESS \\ Is being in paid work beyond state pension age beneficial for health? Evidence from England using a life-course approach
}

\author{
Giorgio Di Gessa, ${ }_{1}^{1}$ Laurie M Corna, ${ }^{2}$ Loretta G Platts, ${ }^{3}$ Diana Worts, ${ }^{4}$ \\ Peggy McDonough, ${ }^{4}$ Amanda Sacker, ${ }^{5}$ Debora Price, ${ }^{6}$ Karen Glaser $^{2}$
}

\begin{abstract}
- Additional material is published online only. To view please visit the journal online (http://dx.doi.org/10.1136/ jech-2016-208086)
\end{abstract}

'Department of Social Policy, The London School of Economics and Political Science, London, UK

Institute of Gerontology, Department of Global Health and Social Medicine, King's College London, London, UK ${ }^{3}$ Stress Research Institute, Stockholm University, Stockholm, Sweden ${ }^{4}$ Dalla Lana School of Public Health, University of Toronto Toronto, Ontario, Canada Institute of Epidemiology \& Health, University College London, London, UK ${ }^{6}$ School of Social Sciences, University of Manchester, Manchester, UK

Correspondence to Dr Giorgio Di Gessa, Department of Social Policy, The London School of Economics and Political Science, London WC2A 2AE, UK ; g.di-gessa@|se.ac.uk

Received 14 July 2016 Accepted 14 November 2016 Published Online First 9 December 2016

\section{(1) CrossMark}

To cite: Di Gessa G, Corna LM, Platts LG, et al. J Epidemiol Community Health 2017:71:431-438.

\section{ABSTRACT}

Background Given the current policy emphasis in many Western societies on extending working lives, we investigated the health effects of being in paid work beyond state pension age (SPA). Until now, work has largely focused on the health of those who exit the labour force early.

Methods Our data come from waves 2-4 of the English Longitudinal Study of Ageing, including the life history interview at wave 3. Using logistic and linear regression models, we assessed the longitudinal associations between being in paid work beyond SPA and 3 measures of health (depression, a latent measure of somatic health and sleep disturbance) among men aged 65-74 and women aged 60-69. Our analyses controlled for baseline health and socioeconomic characteristics, as well as for work histories and health in adulthood and childhood.

Results Approximately a quarter of women and 15\% of men were in paid work beyond SPA. Descriptive bivariate analyses suggested that men and women in paid work were more likely to report better health at follow-up. However, once baseline socioeconomic characteristics as well as adulthood and baseline health and labour market histories were accounted for, the health benefits of working beyond SPA were no longer significant.

Conclusions Potential health benefits of working beyond SPA need to be considered in the light of the fact that those who report good health and are more socioeconomically advantaged are more likely to be working beyond SPA to begin with.

\section{INTRODUCTION}

In response to population ageing and the associated rising costs of pensions, health and social care, many Western governments are pursuing policies designed to extend working lives, including raising the state pension age (SPA). ${ }^{1}$ The UK, like several other European countries, increased SPA for women from 60 to 66 by 2020, and for both sexes to 68 by $2046 .^{2}$ Until now, few studies have addressed the health implications of working at later ages, including beyond SPA.

A large body of evidence suggests that paid work in the prime adult years is generally beneficial for physical and psychological health and well-being. ${ }^{3-5}$ However, research on work and health in later life has mostly focused on the health effects of the event and/or timing of retirement (ie, age at retirement), and in particular on early retirement broadly referring to exits from the labour force before usual retirement ages. ${ }^{6}$ Depending on the health outcome (eg, psychological or physical health), the study design and sample (eg, many earlier studies are based on non-representative occupational cohorts such as GAZEL and Whitehall), the country considered (USA or Europe), its timing, and the reasons given for leaving work (eg, voluntary, ill health, etc), retirement has been found to have beneficial, detrimental or no effects on health. ${ }^{7-15}$ The evidence largely suggests that retirement is associated with an improvement in psychological health and wellbeing, ${ }^{7-9} 15$ but results are less consistent for physical health. ${ }^{9-15}$

However, working post-SPA is a relatively recent trend and so, until now, few studies have focused on the health consequences of continuing work past statutory retirement age while accounting for both health selection and labour market attachment prior to SPA. ${ }^{6}$ For example, a report using the UK British Household Panel Survey suggests that those working beyond SPA report better self-rated health. ${ }^{16}$ However, this study failed to control for health selection into work in later life, a critical limitation given research showing that healthier people are more likely to remain in paid employment, particularly at older ages. ${ }^{17}$ Calvo $e t ~ a l,{ }^{15}$ in one of the few studies to explicitly consider the health effects of continuing work past expected retirement age, as well as accounting for health selection (using an instrumental variable approach), found that older Americans who continued working past 62 (the eligibility age for claiming early Social Security retirement benefits) reported no health benefits, relative to those who retired at this age.

Given recent trends towards working longer, further research is needed on the health consequences of continuing to work past statutory retirement age. Moreover, it is critical to account for earlier health status, but life-course research suggests that lifetime labour market attachment is also likely to affect the relationship between paid work and later life health. ${ }^{18-23}$ For example, McMunn et $a l^{21}$ show that British women who combine family roles with strong labour market attachment are healthier in their mid-50s than those who spend long periods of time out of the labour market looking after the home and family, independent of social position or health earlier in adulthood. Prior employment experiences may also shape decisions about later life work; for example, some may extend their working lives to compensate for earlier interruptions and periods out of the labour market. ${ }^{24}$ 
Against this background, our study draws on a life-course perspective to address two specific research questions. First, we investigate whether or not paid work beyond SPA has a beneficial effect on the health of older adults in England once both earlier health status and lifetime labour market participation are taken into account. Second, we study whether this association differs by hours worked, type of job and social class. We investigate three measures of health: depression, sleep disturbance and somatic health. These indicators of health are all associated with increased mortality and worsened quality of life, even after related covariates are controlled for. ${ }^{25-28}$

\section{METHODS}

\section{Study population}

We used data from the second (2004/2005), third (2006/2007) and fourth waves (2008/2009) of the English Longitudinal Study of Ageing (ELSA), a multidisciplinary longitudinal survey of individuals aged 50 and over living in private households in England (http://www.elsa-project.ac.uk/). Wave 1 data were excluded because nurse-measured health indicators (eg, grip strength) were collected in alternate waves beginning in wave 2 .

Our initial sample included respondents who had reached the current SPA (65 for men, 60 for women) ${ }^{29}$ by wave 3 and who participated in wave 2 . This sample was then further restricted to men aged 65-74 and women aged 60-69 at wave 3. This is because few men and women work beyond 74 and 69, respectively. We also included respondents who participated in wave 4 (ie, excluding those who died $n=36,1.5 \%$ ) for an initial sample size of about 2300 respondents. Of these, however, only 2010 (about 86\%) took part in the life history interview administered at wave 3 , when retrospective histories with information about employment experiences in adulthood and about health in childhood and adulthood were collected. The sample was also further reduced due to loss to follow-up and to missing nurse visit information at wave 4. A total of $\mathrm{N}=2039$ respondents had information collected in waves 2, 3 and 4 (but not necessarily at the life history interview); and $\mathrm{N}=1811$ respondents were present also in the nurse visit at follow-up (although they might have not taken part in the life history interview). In total, $\mathrm{N}=1608$ respondents (ie, about $69 \%$ of the initial sample) were present in all waves, including nurse visits and the life history interview.

\section{Measures}

Outcomes (wave 4)

Our health outcomes are depression, sleep disturbance and somatic health. Symptoms of depression were measured by an abbreviated eight-item version of the validated Centre for Epidemiologic Studies Depression Scale. ${ }^{30}$ Respondents who reported three or more depressive symptoms in the week prior to the interview were classified as being depressed. ${ }^{31}$ Sleep disturbance was assessed with three questions about whether, in the past month, respondents had difficulties falling or staying asleep, and whether they felt tired on waking up. Responses were given a numerical score (ranging from $1=$ 'not during the last month' to $4=$ 'three or more times a week'). As in previous studies, respondents with a score in the lowest sex-specific quartile were categorised as having disturbed sleep. ${ }^{32}$ Finally, as a measure of somatic health, we derived a latent health index using a similar procedure to that proposed by Ploubidis and Grundy. ${ }^{33}$ This index combines both self-reported health (selfrated health $(\mathrm{SRH})$; presence of one or more limitations with activities of daily living (ADL); severe long-standing illness; selfreports of doctor-diagnosed heart disease and stroke; mobility limitations) and nurse-measured information (grip strength). All indicators were recoded such that high values represent good health. Our latent health index assumes that these indicators reflect an underlying common dimension of health, which we refer to as somatic health following Ploubidis and Grundy, ${ }^{33}$ although we recognise that psychological health is also likely to influence an individual's self-assessment of his/her health. This derived latent health index is less subject to measurement error than separate health indicators, and therefore has greater repeatability and reliability. ${ }^{33} 34$

\section{Paid work beyond SPA (wave 3)}

Our key independent variable was a binary indicator which distinguishes respondents by whether they are in paid work or not beyond SPA. Those who reported paid work or self-employment in the month prior to interview at wave 3 were classified as 'in paid work'. Those 'not in paid work' mostly reported being retired (almost 90\% overall). The remaining 10\% could not be considered in more detail given the small number of respondents who classified themselves as sick, homemakers or unemployed.

We also considered alternative measures of paid work which account for work characteristics including working hours, type of work and social class, using them in essence as effect modifiers. In particular, we classified respondents in paid work by working hours/week $(20+$ hours vs $<20$ hours); by level of physical effort involved in their jobs (sedentary occupations vs jobs involving physical exertion); and by social class (distinguishing between higher managerial, administrative and professional occupations; intermediate occupations; and routine and manual occupations following the National Statistics Socio-Economic Classification (NS-SEC)).

\section{Confounders}

\section{Life course (ELSA life history data)}

Individual employment histories-the series of labour market statuses between the ages of 16 and state pension eligibility (64 for men and 59 for women)-were modelled using optimal matching analysis. ${ }^{35}$ In particular, we used an 'ideal type' derivation which compares all observed sequences of work events against a set of ideal type trajectories, ${ }^{36}$ as described fully in Corna et al. ${ }^{37}$ We considered five ideal employment histories for men (employed full-time throughout; not employed throughout; full-time up to 59; early exit at 49; and start of paid work at 23 and exit at 60) and seven for women (employed full-time throughout; employed mostly part time throughout; not employed throughout; early exit at 48; with a short career break between 26 and 30 followed by part time employment; with a long career break between 26 and 41 followed by part time employment; and with a medium career break between 26 and 34 followed by full-time employment). It is important to note that individuals in each of these categories are mostly/always employed or non-employed around the ages indicated because cases are matched to their closest model sequence. Moreover, as controls for life-course health selection, the life histories in wave 3 provided information on health in childhood ( $\mathrm{SRH}$, dichotomised as good, very good or excellent health vs fair or poor) and adulthood (number of periods of ill health or disability lasting more than a year, recoded into two or more periods of ill health vs one or none).

\section{Baseline (wave 2)}

Age, educational level, marital status, wealth, housing tenure, caring responsibilities and health behaviours at baseline (smoking and vigorous physical activity) were included in our analyses as important confounders of the association between 
paid work post-SPA and health in later life. ${ }^{3-5}$ 7-15 Educational level was recoded into three categories (low, middle, high) using the International Standard Classification of Education (http:// www.uis.unesco.org/), where low education refers to below secondary education and a high educational level is defined as having a university education or above. Marital status categories initially distinguished married or cohabiting participants from the never-married, widowed, and separated or divorced. However, given the small number of never-married and widowed respondents in paid work, in our final models we only used a dichotomous variable (married or cohabiting vs unmarried). Wealth is the total net non-housing wealth indicator created by the Institute for Fiscal Studies; ${ }^{38}$ we categorised respondents by whether or not they were in the highest wealth quintile. Housing tenure was recoded into a three-category variable distinguishing outright owners, owners with a mortgage and non-owners. Caring responsibilities were defined as caring for someone in the week prior to the interview; we distinguished between respondents who cared for someone for at least 15 hours/week from those who did so less often, and those who did not provide care. In our final model for men, however, we only considered a dichotomous variable for care and did not consider the number of hours of care provided. Finally, in addition to depression and the latent somatic health measures at baseline (see above for derivation), we also controlled for smoking (whether or not a current smoker) and vigorous physical activity (once a week or more compared with less often). It was not possible to control for sleep disturbance at baseline as this was not collected at wave 2 .

\section{Statistical analyses}

We assessed the longitudinal relationship between paid work at wave 3 and health at wave 4, controlling for demographic characteristics, socioeconomic factors and health behaviours at wave 2 (baseline), and employment histories as potential confounders. Importantly, we also adjust for health throughout the life course to account for health selection into paid work beyond SPA. In the light of significant gender differences in labour market histories, health status and SPA in England, we carried out analyses separately for men and women. We also repeated analyses by type of work, working hours and social class as described above in the Paid work beyond SPA (wave 3) section. We used logistic regression when depression and sleep disturbance were considered, and linear regression for the continuous somatic health variable. Models were initially estimated using complete case analyses (not shown). However, about up to $21 \%$ of the sample had at least one missing value (particularly with respect to the life history information). Using the multiple

Table 1 Per cent (and N) distribution of baseline and life history health, demographic, and socioeconomic characteristics, by gender and paid work post state pension age

\begin{tabular}{|c|c|c|c|c|c|c|}
\hline & \multicolumn{3}{|l|}{ Men } & \multicolumn{3}{|l|}{ Women } \\
\hline & $\begin{array}{l}\text { Not in paid work } \\
\text { at wave } 3\end{array}$ & $\begin{array}{l}\text { In paid work } \\
\text { at wave } 3\end{array}$ & $\mathrm{p}$ Value & $\begin{array}{l}\text { Not in paid work } \\
\text { at wave } 3\end{array}$ & $\begin{array}{l}\text { In paid work } \\
\text { at wave } 3\end{array}$ & p Value \\
\hline \multicolumn{7}{|l|}{ Baseline (wave 2) characteristics } \\
\hline Depression & $15.1(111)$ & $10.3(13)$ & NS & $25.1(216)$ & $17.0(49)$ & $* * *$ \\
\hline Sleep disturbance* & $28.7(187)$ & $20.0(24)$ & ** & $32.0(252)$ & $26.9(71)$ & NS \\
\hline Somatic health (mean) $\dagger$ & -0.026 & 0.345 & $* * *$ & -0.180 & 0.182 & $* * *$ \\
\hline Not smoking & $84.6(620)$ & $90.5(114)$ & NS & $84.4(724)$ & $84.7(243)$ & NS \\
\hline Vigorous physical activity $1+/$ week & 22.7 (197) & $21.1(30)$ & NS & $16.6(167)$ & $24.7(83)$ & $* * *$ \\
\hline Age (mean) & 69.7 & 68.5 & $* * *$ & 64.7 & 62.7 & $* * *$ \\
\hline Never married & $5.3(39)$ & $1.6(2)$ & NS & $3.4(29)$ & $3.1(9)$ & $* * *$ \\
\hline Married/cohabiting & 77.9 (572) & 84.9 (107) & & $69.3(597)$ & $68.5(198)$ & \\
\hline Divorced/separated & $8.6(63)$ & $10.3(13)$ & & $12.4(107)$ & $19.4(56)$ & \\
\hline Widowed & $8.2(60)$ & $3.2(4)$ & & 14.9 (128) & $9.0(26)$ & \\
\hline No education & 33.7 (246) & $23.8(30)$ & ** & $38.6(331)$ & $25.0(72)$ & $* * *$ \\
\hline Some education & $39.0(270)$ & $35.7(45)$ & & $40.9(351)$ & $41.7(120)$ & \\
\hline High education & $29.3(214)$ & $40.5(51)$ & & 20.5 (176) & $33.3(96)$ & \\
\hline Highest wealth quintile & 18.9 (137) & $27.9(34)$ & ** & 19.6 (167) & $23.9(67)$ & NS \\
\hline Own outright & $75.4(553)$ & $71.4(90)$ & NS & $72.2(621)$ & $59.9(173)$ & $* * *$ \\
\hline Mortgage & $10.1(74)$ & $15.1(19)$ & & $14.1(121)$ & $32.5(94)$ & \\
\hline Rent & $14.5(106)$ & $13.5(17)$ & & $13.7(118)$ & $7.6(22)$ & \\
\hline No care provided & $90.7(666)$ & $94.4(119)$ & NS & $83.9(722)$ & $87.9(254)$ & ** \\
\hline Cared $<15$ hours/week & $5.3(39)$ & $4.0(5)$ & & $7.2(62)$ & $8.0(23)$ & \\
\hline Cared $15+$ hours/week & $4.0(29)$ & $1.6(2)$ & & $8.9(77)$ & $4.1(12)$ & \\
\hline \multicolumn{7}{|l|}{ Life course } \\
\hline Ever left employer because of ill health & $22.2(163)$ & $8.7(11)$ & $* * *$ & $25.6(220)$ & $9.7(28)$ & $* * *$ \\
\hline 2 or more periods of ill health in adulthood & $15.7(115)$ & $6.4(8)$ & $* * *$ & $20.2(174)$ & $6.9(20)$ & $* * *$ \\
\hline SRH as good, very good or excellent in childhood & $88.3(648)$ & $92.0(115)$ & NS & $83.4(717)$ & $90.0(260)$ & $* * *$ \\
\hline Total respondents ( $\mathrm{N}$ ) & $85.4 \%(734)$ & $14.6 \%(126)$ & & $74.9 \%(861)$ & $25.1 \%(289)$ & \\
\hline
\end{tabular}


imputation (MI) approach which assumes that data are missing at random rather than completely at random, ${ }^{39} 40$ we ran imputations separately by gender using chained equations (20 cycles; repeated independently 50 times). The results of these analyses were then combined using Rubin's rules. ${ }^{39}$ Since the results for the complete case and the imputed data sets were broadly similar,

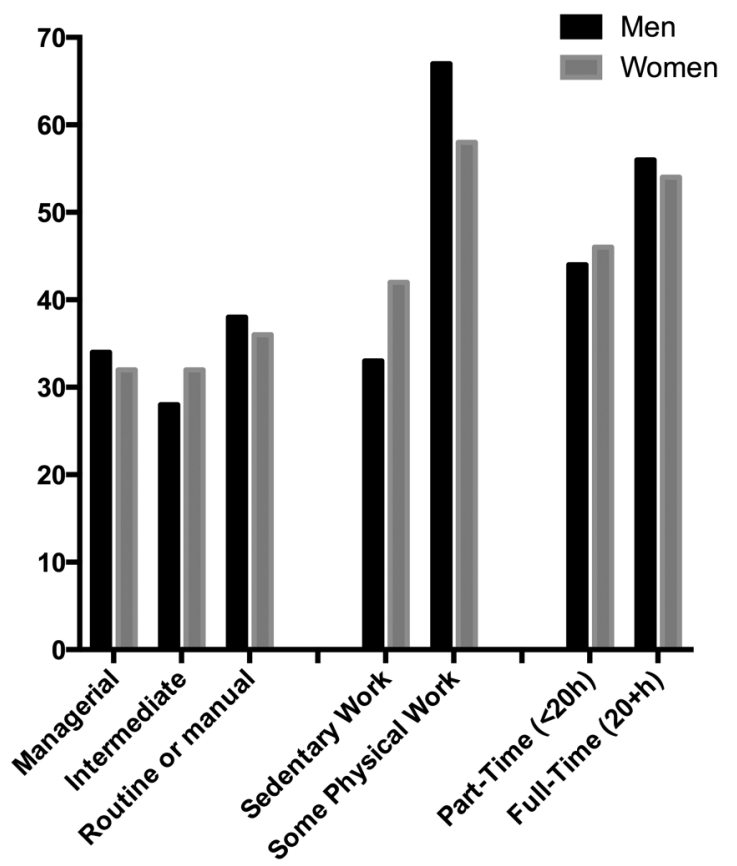

Figure 1 Percent distribution of work characteristics among respondents in paid work, by gender. Source: English Longitudinal Study of Ageing (ELSA), 2006/2007. Analyses restricted to male respondents aged 65-74 $(\mathrm{N}=126)$ and female respondents aged 60-69 $(\mathrm{N}=289)$ who were in paid work. in this paper we present models for the imputed data sets restricted to respondents who had complete information for the health outcomes considered. Latent summaries were estimated using Mplus 7.3; all analyses were performed in STATAV.13.

\section{RESULTS}

\section{Measurement model for the latent measure of somatic health}

In order to summarise measures of somatic health, we considered a unidimensional model, where a single latent factor accounts for variation in self-reported and observer-measured health indicators. As shown in online supplementary table A, all health indicators significantly loaded on the latent factor, with good self-rated health, and the absence of ADL, mobility limitations and severe long-standing illness having the strongest standardised factor loadings (with values around 0.80 ). Goodness of fit criteria indicate that the model fits the data well. The latent variable obtained by combining the health indicators offers a continuous health measure, where positive high scores indicate good somatic health. Its estimated distribution is essentially Gaussian (mean $=-0.04 ; \mathrm{SD}=0.74$ ), although slightly skewed left (skewness $=-0.34)$.

\section{Descriptive statistics}

The characteristics of the male and female respondents who were successfully interviewed at wave 2 , wave 3 and in the life history; and who were aged 65-74 and 60-69, respectively, also at wave $3(\mathrm{~N}=2010)$ are shown in table 1 . About $25 \%$ of older women and $15 \%$ of men reported working beyond SPA. This is comparable to data from the Labour Force Survey which shows that $22 \%$ of women aged $60-69$ and $14 \%$ of men aged $65-74$ were in paid employment in the UK in 2006. Overall, men and women in good health were more likely to be in paid work post-SPA at wave 3 , as were those in better health throughout their lives (ie, had fewer than two spells of ill health in adulthood, and good health in childhood), and those with

Table 2 Per cent (and N) distribution of life-course labour market histories, by paid work post-SPA

\begin{tabular}{|c|c|c|c|}
\hline & Not in paid work at W3 & In paid work at W3 & All sample \\
\hline \multicolumn{4}{|l|}{ Men } \\
\hline \multicolumn{4}{|l|}{ Continuous work up to SPA } \\
\hline Mostly FT throughout to SPA & $40.4(296)$ & $75.6(93)$ & $45.4(389)$ \\
\hline \multicolumn{4}{|l|}{ Weak labour market attachment } \\
\hline Mostly non-employed throughout & $4.9(36)$ & $0.8(1)$ & $4.3(37)$ \\
\hline FT very early exit (at about age 49) & $12.7(93)$ & $4.1(5)$ & $11.5(98)$ \\
\hline \multicolumn{4}{|l|}{ Continuous work up to about age 60} \\
\hline FT early exit (at about age 60) & $33.6(246)$ & $5.7(7)$ & $29.6(253)$ \\
\hline Late start at about age 23 , early exit (at about age 60 ) & $8.5(62)$ & $13.8(17)$ & $9.2(79)$ \\
\hline \multicolumn{4}{|l|}{ Women } \\
\hline \multicolumn{4}{|l|}{ Continuous work FT or PT up to SPA } \\
\hline Mostly PT throughout to SPA & $5.2(45)$ & $7.3(21)$ & $5.7(66)$ \\
\hline Mostly FT throughout to SPA & $25.3(217)$ & $30.6(88)$ & $26.6(305)$ \\
\hline \multicolumn{4}{|l|}{ Weak labour market attachment } \\
\hline Mostly non-employed throughout/family carer & $21.4(184)$ & $4.2(12)$ & $17.1(196)$ \\
\hline Early exit (at about age 48 ) & $9.7(83)$ & $0.7(2)$ & $7.4(85)$ \\
\hline \multicolumn{4}{|l|}{ Paid work up to SPA with family care interruptions } \\
\hline Long break (about ages 26-41) to PT up to SPA & $10.4(89)$ & $16.0(46)$ & $11.8(135)$ \\
\hline Short break (about ages 26-30) to PT up to SPA & $11.4(98)$ & $18.8(54)$ & $13.3(152)$ \\
\hline Medium break (about ages $26-34$ ) to FT up to SPA & $16.6(143)$ & $22.6(65)$ & $18.1(208)$ \\
\hline
\end{tabular}




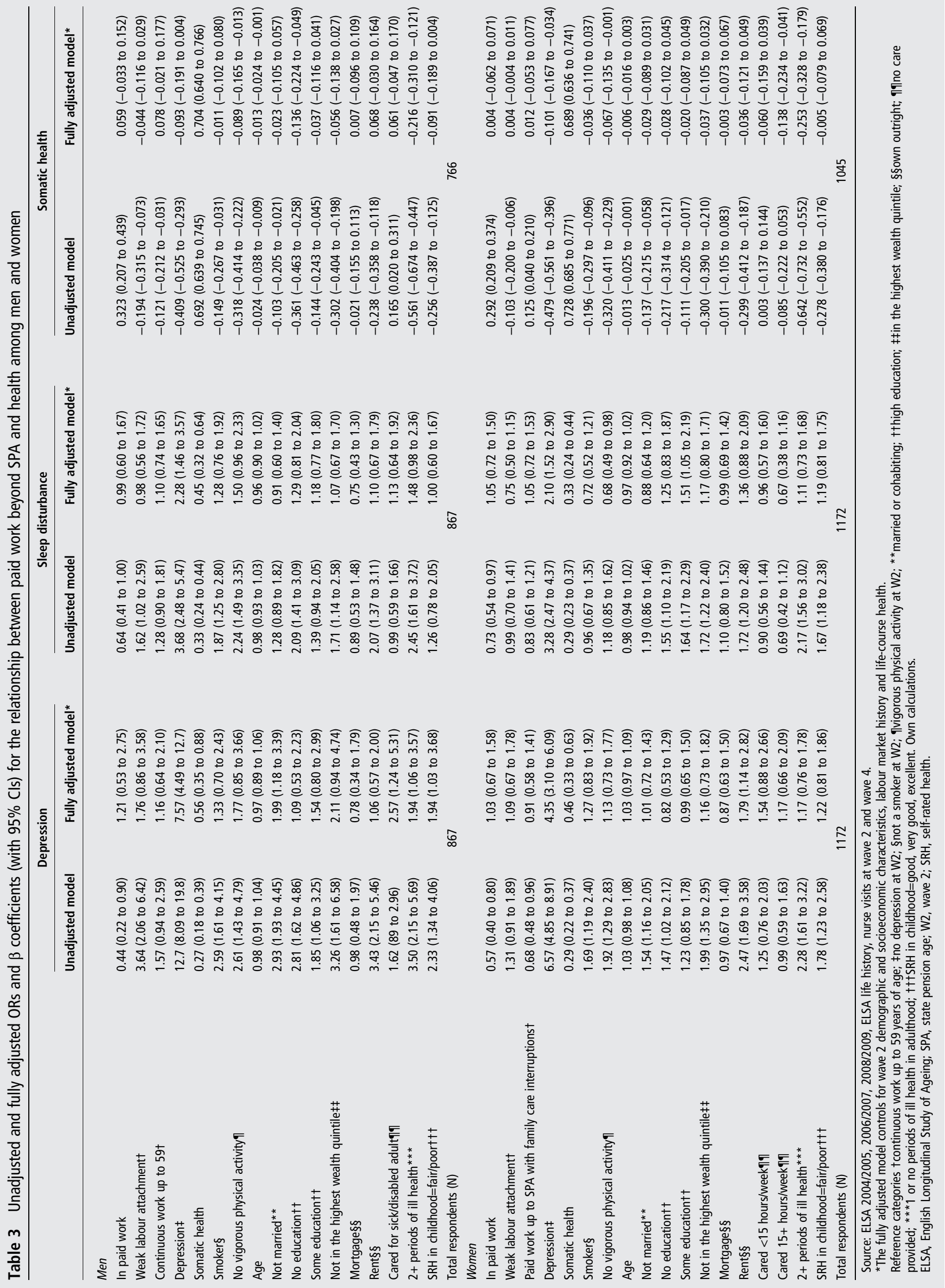


Table 4 Unadjusted and fully adjusted ORs and $\beta$ coefficients (with $95 \% \mathrm{Cls}$ ) for the relationship between three different characteristics of paid work beyond state pension age and health among men and women

\begin{tabular}{|c|c|c|c|c|c|c|}
\hline & \multicolumn{2}{|c|}{ Depression } & \multicolumn{2}{|c|}{ Sleep disturbance } & \multicolumn{2}{|c|}{ Somatic health } \\
\hline & Unadjusted model & Fully adjusted model ${ }^{*}$ & Unadjusted model & Fully adjusted model* & Unadjusted model & Fully adjusted model* \\
\hline \multicolumn{7}{|l|}{ Men } \\
\hline In work, sedentary & $0.46(0.14$ to 1.53$)$ & $1.88(0.52$ to 6.81$)$ & $0.49(0.21$ to 1.13$)$ & 0.96 (0.39 to 2.37$)$ & $0.367(0.176 ; 0.557)$ & $0.008(-0.141$ to 0.157$)$ \\
\hline In work, physical & 0.44 (0.19 to 1.03$)$ & 0.98 (0.38 to 2.49$)$ & $0.71(0.42$ to 1.20$)$ & $0.98(0.54$ to 1.77$)$ & $0.302(0.162 ; 0.440)$ & 0.051 (-0.061 to 0.162$)$ \\
\hline Not in paid work & REF & REF & REF & REF & REF & REF \\
\hline In work, part time & $0.43(0.15$ to 1.22$)$ & $1.11(0.37$ to 3.29$)$ & 0.62 (0.32 to 1.18$)$ & $0.91(0.45$ to 1.85$)$ & $0.307(0.137 ; 0.476)$ & $0.061(-0.071$ to 0.192$)$ \\
\hline In work, full-time & 0.47 (0.18 to 1.18$)$ & 1.25 (0.45 to 3.48$)$ & 0.67 (0.37 to 1.21$)$ & 1.05 (0.54 to 2.03$)$ & $0.332(0.182 ; 0.482)$ & $0.010(-0.110$ to 0.129$)$ \\
\hline Not in paid work & REF & $R E F$ & REF & REF & REF & $R E F$ \\
\hline In work, managerial & $0.62(0.22$ to 1.77$)$ & $1.46(0.42$ to 6.32$)$ & 0.85 (0.41 to 1.71$)$ & 1.60 (0.75 to 3.59$)$ & $0.311(0.122 ; 0.499)$ & $-0.051(-0.200 ; 0.097)$ \\
\hline In work, intermediate & $0.43(0.20$ to 1.94$)$ & 1.09 (0.36 to 3.42$)$ & $0.37(0.14$ to 0.97$)$ & 0.59 (0.22 to 1.59$)$ & $0.259(0.048 ; 0.470)$ & $0.048(-0.112 ; 0.210)$ \\
\hline In work, routine/manual & 0.67 (0.26 to 1.73$)$ & 1.12 (0.37 to 3.31$)$ & 0.69 (0.34 to 1.38$)$ & 0.87 (0.40 to 1.89$)$ & $0.380(0.201 ; 0.559)$ & $0.105(-0.037 ; 0.247)$ \\
\hline Not in paid work & REF & REF & REF & REF & REF & $R E F$ \\
\hline Total respondents $(\mathrm{N})$ & \multicolumn{2}{|r|}{867} & \multicolumn{2}{|r|}{867} & \multicolumn{2}{|r|}{766} \\
\hline \multicolumn{7}{|l|}{ Women } \\
\hline In work, sedentary & 0.51 (0.30 to 0.86$)$ & 0.98 (0.54 to 1.78$)$ & $0.92(0.61$ to 0.19$)$ & $1.40(0.86$ to 2.26$)$ & 0.307 (0.188 to 0.426$)$ & $-0.018(-0.109 ; 0.072)$ \\
\hline In work, physical & 0.62 (0.40 to 0.95$)$ & 1.03 (0.63 to 1.70$)$ & 0.59 (0.40 to 0.87$)$ & $0.80(0.52$ to 1.24$)$ & 0.281 (0.178 to 0.383 ) & $0.013(-0.065$ to 0.092$)$ \\
\hline Not in paid work & REF & REF & REF & REF & REF & REF \\
\hline In work, part time & 0.53 (0.31 to 0.87$)$ & $0.86(0.49$ to 1.51$)$ & 0.77 (0.51 to 1.18$)$ & 1.02 (0.64 to 1.62$)$ & $0.261(0.147 ; 0.376)$ & $0.013(-0.073$ to 0.115$)$ \\
\hline In work, full-time & $0.62(0.40$ to 0.96$)$ & $1.21(0.72$ to 2.05$)$ & $0.68(0.47$ to 1.00$)$ & $1.01(0.64$ to 1.60$)$ & $0.328(0.221$ to 0.434$)$ & $0.003(-0.082$ to 0.087$)$ \\
\hline Not in paid work & REF & REF & REF & REF & REF & REF \\
\hline In work, managerial & 0.37 (0.19 to 0.73$)$ & 0.83 (0.40 to 1.74$)$ & 0.83 (0.51 to 13.4$)$ & 1.55 (0.86 to 2.80$)$ & $0.401(0.27 ; 0.534)$ & $0.045(-0.061$ to 0.151$)$ \\
\hline In work, intermediate & $0.75(0.45$ to 1.25$)$ & $1.35(0.73$ to 2.47$)$ & $0.82(0.51$ to 1.30$)$ & $1.09(0.65$ to 1.87$)$ & $0.257(0.123$ to 0.390$)$ & $-0.026(-0.124$ to 0.074$)$ \\
\hline In work, routine/manual & $0.58(0.33$ to 1.00$)$ & $0.86(0.45$ to 1.61$)$ & 0.57 (0.35 to 0.94$)$ & $0.70(0.41$ to 1.18$)$ & 0.226 (0.101 to 0.352$)$ & $-0.010(-0.107$ to 0.085$)$ \\
\hline Not in paid work & REF & REF & REF & REF & REF & $R E F$ \\
\hline Total respondents $(\mathrm{N})$ & \multicolumn{2}{|r|}{1172} & \multicolumn{2}{|r|}{1172} & \multicolumn{2}{|c|}{1045} \\
\hline
\end{tabular}

postsecondary education. Marital status, home tenure and caring responsibilities at baseline were associated with work post-SPA only among women: female respondents divorced or separated, those with an unpaid mortgage, and those who did not provide care were more likely to be in paid work post-SPA at wave 3 .

\section{Current and lifetime paid work characteristics}

Figure 1 shows the employment characteristics of respondents who worked beyond SPA. About one-third were in managerial positions, almost half (45\%) worked <20 hours/week, and one-third of male and $41 \%$ of female workers had a sedentary job. No significant gender differences were found in these characteristics.

Table 2 presents the classification of respondents' employment histories for the sample and by whether they engaged in paid work post-SPA. Results suggest that men and women who worked throughout their lives up to SPA (full-time or part time, with or without career breaks) were more likely to be in paid work after SPA. However, given the small number of cases in some categories, we combined them in order to create categories that included respondents with conceptually similar employment histories. In our multivariate model, we considered only three categories for both men (continuous work up to SPA, continuous work up to about age 60, and weak labour market attachment) and women (continuous work either full-time or part time up to SPA, paid work up to SPA with family care interruptions of any length, and weak labour market attachment including leaving the labour market at about age 48).
Per cent distribution of work characteristics among respondents in paid work, by gender (figure 1).

\section{Associations between work beyond SPA and health at follow-up}

Table 3 shows the longitudinal associations between paid work beyond SPA and health for men and women, respectively. For each health outcome, we present unadjusted and fully adjusted results. The unadjusted estimates show that men and women in paid work were more likely to be in better health at follow-up than those not in paid work. For instance, respondents in paid work beyond SPA were between 0.44 (men) and 0.57 (women) times less likely to be depressed, and between 0.64 (men) and 0.73 (women) times less likely to report sleep disturbance. They were also significantly more likely to report better somatic health ( $\beta=0.323$ for men, and $\beta=0.292$ for women). However, for all three health indicators considered, the beneficial effect of paid work was not observed once the other covariates were included.

In the fully adjusted models, baseline and life-course health covariates remained significantly associated with the three outcomes. Having had two or more periods of illness in adulthood increased the odds of reporting depression and sleep disturbance among men by a factor of 1.94 and 1.48 , respectively; male ( $\beta=$ $-0.216)$ and female $(\beta=-0.253)$ respondents also were in significantly poorer somatic health. Finally, unadjusted results showed negative associations between weak labour market attachment and good health for men (all health outcomes) and women (for somatic health only). 
Table 4 shows results obtained when alternative characteristics of paid work were considered. Fully adjusted results suggest that paid work beyond SPA does not have differential effects on health depending on characteristics of the job such as physical demand, hours worked or social class.

\section{CONCLUSION AND DISCUSSION}

Many Western societies are raising SPA. However, the health effects of extending employment are not fully understood. Using a life-course approach, this study investigated whether employment beyond SPA is beneficial for health once both prior health status and work histories are taken into account. ELSA's rich data and large representative sample allowed us to adjust for some key life-course health characteristics as well as labour market histories that may confound the association between work beyond SPA and subsequent somatic and psychological health. Similar to Calvo et al's ${ }^{15}$ findings, our results also suggest that being in paid work beyond SPA is not associated with better (or detrimental) health. This is most likely because only a select group of healthy older adults works beyond SPA.

Our contribution should be considered in the light of several limitations. First, although a number of different elements of paid work were considered, we were not able to fully capture other key dimensions of work beyond SPA. For instance, we do not know the reasons why respondents worked beyond SPA as this information was not collected until wave 4 . We were also not able to explore effort and reward imbalances at work as these questions were only asked in the drop-off questionnaire (and this would have further reduced the analytical sample size). Moreover, in constructing labour market histories, we clustered individuals whose trajectories are similar but not identical, and thus we cannot say whether this 'muddied' associations with subsequent health or with the other independent variables. Second, it was not possible to consider lifetime social class as information on usual social class is not available in ELSA. Third, among life-course health controls, we were limited by data availability: we were not able to consider the presence or the timing of the onset of specific health conditions, but we should also acknowledge that the measures of health in childhood and adulthood used are rather broad proxies for pre-SPA health. Also, while in our analysis baseline characteristics were considered confounders, some of these same variables might act as mediators/effect modifiers if measured after SPA (for instance, caring might mediate/moderate the working to health relationship). Finally, a 2-year period may have been too short to observe a relationship between paid work beyond SPA and subsequent health.

In summary, our analysis suggests that extending working lives may not have beneficial effects on health. The decision and the ability to continue working beyond SPA seems to be strongly affected by prior health. Respondents with two or more periods of ill health were most likely to report that they experienced such problems in their $50 \mathrm{~s}$ and $60 \mathrm{~s}$, with about one-third reporting that periods of ill health limited their opportunities for paid work. However, these findings do not rule out the possibility that changes to SPA may worsen population health, if everyone is required to work longer, including people in poor health.

Although more research is needed to investigate when ill health matters most for work exits, and whether our results will also hold for future generations, our analyses suggest that the ability to work longer hinges on both current and lifetime health. Optimising and promoting health throughout the life course seems key to policies aimed at extending working lives.

\section{What is already known on this subject}

- Participation in paid work is associated with good health in adulthood. However, little work has examined the health implications of labour market participation among those who continue to work post state pension age (SPA).

- Evidence on the impact of retirement on health largely suggests beneficial effects for psychological well-being (results are less consistent for physical health), even when health selection is addressed. However, most studies focus on early retirement with few explicitly investigating how continuing work beyond SPA affects later life health.

- In addition, few studies have explicitly examined the relationship between working beyond SPA and later life health while also considering both earlier health status and lifetime labour market experience.

\section{What this study adds}

- Adopting a life-course approach, this research study investigates whether employment beyond SPA is beneficial for health, using nationally representative data on England and considering health selection effects into paid work and life-course labour market participation.

- Our results suggest no beneficial or detrimental effects of continuing to work past statutory retirement age when both earlier health status and work histories are taken into account. This is most likely because only a select group of healthy older adults work beyond statutory retirement age.

Acknowledgements The data were made available through the UK Data Archive. ELSA was developed by a team of researchers based at the NatCen Social Research, University College London and the Institute for Fiscal Studies. The data were collected by NatCen Social Research. The funding is provided by the National Institute of Aging in the United States, and a consortium of UK government departments co-ordinated by the Office for National Statistics. The developers and funders of ELSA and the Archive do not bear any responsibility for the analyses or interpretations presented here.

Contributors GDG conducted the analyses, drafted the article, contributed to the study design and co-led the interpretation of data with KG and LC. KG, LC and DP led the conception and design of the study, supervised the analyses, co-led the interpretation of data with GDG and contributed to manuscript revisions. LGP, AS, PM and DW led the construction and conceptualisation of the employment trajectories. AS and PM have also critically reviewed the manuscript and contributed to the interpretation of data. All authors have read and approved the final version.

Funding This study was funded by the British cross-research council Lifelong Health and Wellbeing (LLHW) programme under Extending Working Lives as part of an interdisciplinary consortium on Wellbeing, Health, Retirement and the Lifecourse (WHERL) (ES/L002825/1); and by the Canadian Institutes of Health Research (grand number MOP 11952) and the Social Sciences and Humanities Research council (grant number 435121267).

Disclaimer The developers and funders of ELSA and the Archive do not bear any responsibility for the analyses or interpretations presented here.

Competing interests None declared.

Ethics approval Ethical approval for all the ELSA waves was granted from the National Research and Ethics Committee. 
Provenance and peer review Not commissioned; externally peer reviewed.

Open Access This is an Open Access article distributed in accordance with the terms of the Creative Commons Attribution (CC BY 4.0) license, which permits others to distribute, remix, adapt and build upon this work, for commercial use, provided the original work is properly cited. See: http://creativecommons.org/licenses/ by/4.0/

\section{REFERENCES}

1 OECD. Ageing and employment: live longer, work longer. Paris, France: OECD Publications, 2006.

2 Ginn J. Austerity and inequality. Exploring the impact of cuts in the UK by gender and age. Res Ageing Soc Policy 2013;1:28-53.

3 Graetz B. Health consequences of employment and unemployment: longitudinal evidence for young men and women. Soc Sci Med 1993;36:715-24.

4 Klumb PL, Lampert T. Women, work, and well-being 1950-2000: a review and methodological critique. Soc Sci Med 2004;58:1007-24.

5 Woodell G, Burton AK. Is work good for your health and well-being? Department for Work and Pensions. London: The Stationery Office, 2006.

6 Fisher GG, Chaffee DS, Sonnega A. Retirement timing: a review and recommendations for future research. Work Aging Retirement 2016;2:230-61.

7 Mein G, Martikainen P, Hemingway $H$, et al. Is retirement good or bad for mental and physical functioning? Whitehall II longitudinal study of civil servants. J Epidemiol Community Health 2003;57:46-9.

8 Westerlund $\mathrm{H}$, Vahtera J, Ferrie JE, et al. Effect of retirement on major chronic conditions and fatigue: French GAZEL occupational cohort study. BMJ 2010;341:c6149.

9 Jokela M, Ferrie JE, Gimeno D, et al. From midlife to early old age: health trajectories associated with retirement. Epidemiology 2010;21:284-90.

10 Moon JR, Glymour MM, Subramanian SV, et al. Transition to retirement and risk of cardiovascular disease: prospective analysis of the US Health and Retirement Study. Soc Sci Med 2012;75:526-30.

11 Westerlund $H$, Kivimäki M, Singh-Manoux A, et al. Self-rated health before and after retirement in France (GAZEL): a cohort study. Lancet 2009;374:1889-96.

12 Coe NB, Zamarro G. Retirement effects on health in Europe. J Health Econ 2011;30:77-86.

13 Hyde $M$, Ferrie J, Higgs $P$, et al. The effects of pre-retirement factors and retirement route on circumstances in retirement: findings from the Whitehall II study. Ageing Soc 2004;24:279-96.

14 Hessel P. Does retirement (really) lead to worse health among European men and women across all educational levels? Soc Sci Med 2016;151:19-26.

15 Calvo E, Sarkisian N, Tamborini CR. Causal effects of retirement timing on subjective physical and emotional health. J Gerontol B Psychol Sci Soc Sci 2013;68:73-84.

16 Smeaton D, McKay S. Working after state pension age: quantitative analysis. London: Department for Work and Pensions, 2003.

17 Schuring $M$, Burdorf $L$, Kunst $A$, et al. The effects of ill health on entering and maintaining paid employment: evidence in European countries. J Epidemiol Community Health 2007:61:597-604.

18 Bartley M, Plewis I. Accumulated labour market disadvantage and limiting long-term illness: data from the 1971-1991 Office for National Statistics' Longitudinal Study. Int J Epidemiol 2002;31:336-41.

19 Stone J, Evandrou M, Falkingham J, et al. Vlachantoni, women's economic activity trajectories over the life course: implications for the self-rated health of women aged 64+ in England. J Epidemiol Community Health 2015;69:873-9.
20 Wahrendorf M. Previous employment histories and quality of life in older ages: sequence analyses using SHARELIFE. Ageing Soc 2015;35:1928-59.

21 McMunn A, Bartley M, Hardy R, et al. Life course social roles and women's health in mid-life: causation or selection? J Epidemiol Community Health 2006;60:484-9.

22 Lacey RE, Sacker A, Kumari M, et al. Work-family life courses and markers of stress and inflammation in mid-life: evidence from The National Child Development Study. Int J Epidemiol 2016;45:1247-59.

23 Blane $D$, Higgs $P$, Hyde $M$, et al. Life course influences on quality of life in early old age. Soc Sci Med 2004;58:2171-9.

24 Finch N. Why are women more likely than men to extend paid work? The impact of work-family life history. Eur J Ageing 2013;11:31-9.

25 Saz P, Dewey ME. Depression, depressive symptoms and mortality in persons aged 65 and over living in the community: a systematic review of the literature. Int J Geriatr Psychiatry 2001;16:622-30.

26 Idler EL, Benyamini Y. Self-rated health and mortality: a review of twenty-seven community studies. J Health Soc Behav 1997;38:21-37.

27 Neikrug AB, Ancoli-Israel S. Sleep disorders in the older adult-a mini-review. Gerontology 2010;56:181-9.

28 Cooper R, Kuh D, Hardy R. Objectively measured physical capability levels and mortality: systematic review and meta-analysis. BMJ 2010;341:c4467.

29 Bozio A, Crawford R, Tetlow G. The history of state pensions in the UK: 1948 to 2010, in briefing note No. 105. London: Institute for Fiscal Studies, 2010.

30 Beekman AT, Deeg DJ, Van Limbeek J, et al. Criterion validity of the Center for Epidemiologic Studies Depression scale (CES-D): results from a community-based sample of older subjects in the Netherlands. Psychol Med 1997;27:231-5

31 Schane RE, Walter LC, Dinno A, et al. Prevalence and risk factors for depressive symptoms in persons with chronic obstructive pulmonary disease. J Gen Intern Med 2008:23:1757-62.

32 Jackowska M, Kumari M, Steptoe A. Sleep and biomarkers in the English Longitudinal Study of Ageing: associations with C-reactive protein, fibrinogen, dehydroepiandrosterone sulfate and hemoglobin. Psychoneuroendocrinology 2013;38:1484-93.

33 Ploubidis GB, Grundy E. Health measurement in population surveys: combining information from self-reported and observer-measured health indicators. Demography 2011;48:699-724.

34 Boniface DR, Tefft ME. The application of structural equation modelling to the construction of an index for the measurement of health-related behaviours. J $R$ Stat Soc Ser D (Statistician) 1997;46:505-14.

35 Abbott A, Tsay A. Sequence analysis and optimal matching methods in sociology: review and prospect. Soc Methods Res 2000;29:3-33.

36 Wiggins RD, Erzberger $C$, Hyde $M$, et al. Optimal matching analysis using ideal types to describe the lifecourse: an illustration of how histories of work, partnerships and housing relate to quality of life in early old age. Int J Soc Res Methodol 2007;10:259-78.

37 Corna LM, Platts L, Worts $\mathrm{D}$, et al. A sequence analysis approach to modelling the work and family histories of older adults in the UK. Vol. ISBN 978-1-908951-18-2. London: King's College London, 2016.

38 Oldfield Z. Financial derived variables ELSA waves 1-4, in user guides. London: Institute for Fiscal Studies, 2011.

39 Little RJA, Rubin DB. Statistical analysis with missing data. New York: Wiley, 2002.

40 Marshall A, Altman DG, Royston P, et al. Comparison of techniques for handling missing covariate data within prognostic modelling studies: a simulation study. BMC Med Res Methodol 2010;10:7. 